\title{
Investigating the influence of dredged material stabilized by pozzolanic binders on geotechnical properties
}

\author{
SILITONGA, E ${ }^{1}$, LEVACHER, $\mathrm{D}^{2}$, MEZAZIGH, $\mathrm{S}^{3}$ SHRIVASTAVA, $\mathrm{A}^{4}$ \\ ${ }^{1}$ Doctoral student, ${ }^{2}$ Professor, ${ }^{3}$ Lecturer, ${ }^{4}$ Invited Researcher. \\ University of Caen, U.M.R., CNRS 6143 M2C, 24 rue des Tilleuls 14000, Caen, France. \\ ${ }^{1}$ ernesto.silitonga@.unicaen.fr, ${ }^{2}$ daniel.levacher@unicaen.fr; \\ 3 salim.mezazigh@unicaen.fr, ${ }^{4}$ abhaykshrivastava@yahoo.co.in
}

Keywords: Dredged sediments, fly ash, unconfined compressive strength, cyclic wetting-drying test, freeze and thaw test

\section{Introduction}

In France, the beneficial use of dredged sediment in road construction is one of the main applications. Previous studies concerning the potential use of dredged sediments as a material filler and in road construction was performed in the laboratory by several researchers. [1] 2] [3] [4]. The previous experiments used cement and lime as a binder. In this study we tried to replace fly ash as alternative binders. It has been known that the addition of fly ash improves the geotechnical properties, due to the pozzolanic reaction and its role as a micro-filler. Usually, material stabilized with fly ash needs a longer curing period than conventional binders such as cement and lime, due to their pozzolanic reaction, which bring a slow development of strength at early ages, especially when a large amount of fly ash is used. To achieve effectiveness of fly ash on soil stabilization work, some researchers added a small amount of lime [5]. Trying to make a more productive use of fly ash would have considerable environmental benefits, reducing air and water pollution. Increased use as a partial cement or lime replacement would also represent savings in energy because fly ash has been called a high-energy- based material.

\section{Materials.}

This study was performed using the dredged sediments from Port of Cherbourg, France. Two types of fly ash (FA) were used in this part of the main research: named Sodeline (SD) and Soproline (SP). These two FA were produced respectively from different bituminous coal and limestone feed coals from fluidized-bed power plant.

\subsection{Particle size.}

It is well known that particles size distribution is one of important factor beside packing effect and smoothness of surface texture, to control the water demand and workability of the mixture. A previous work [6] [7] showed that calcium content, the size distribution and the shape of the particle of fly ash were the most important parameter governing the strength development rate. Z. Giergiczny and 
A. Werynska [8] claimed that the coarse fly ash gained very low compressive strength when its addition was used more than $30 \%$ of cement replacements. The experiment study by Benici et al [9] showed that the specimen with a better fineness and a narrower particle size distribution had the highest compressive strength, sulfate resistance than the others specimens. According to Joshi and Lohtia [10], the influence of the finer particle size of fly ash produces more reactive pozzolanic reaction because smaller particle size of fly ash with a higher surface area and glassy phase content also improved the pozzolanic reaction.

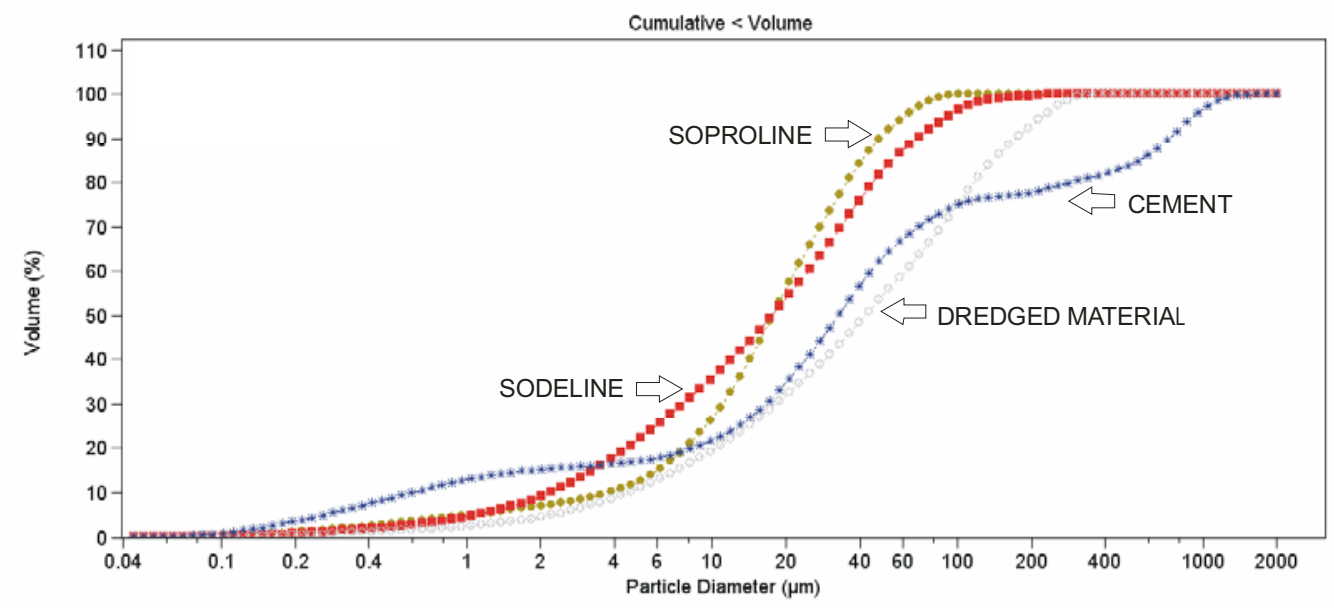

Fig.1.Particle size distribution of the dredged sediment, cement and 2 types of fly ashes

\begin{tabular}{ccccccc}
\hline Particle size & $\mathrm{D}_{10}(\mu \mathrm{m})$ & $\mathrm{D}_{50}(\mu \mathrm{m})$ & $\mathrm{D}_{90}(\mu \mathrm{m})$ & $\begin{array}{c}\text { Clay (\%) } \\
<2 \mu \mathrm{m}\end{array}$ & $\begin{array}{c}\text { Silts (\%) } \\
2-63 \mu \mathrm{m}\end{array}$ & $\begin{array}{c}\text { Sand (\%) } \\
>63 \mu \mathrm{m}\end{array}$ \\
\hline $\begin{array}{c}\text { Dredged } \\
\text { sediment }\end{array}$ & 172.4 & 42.12 & 4.517 & 4.52 & 56.6 & 38.88 \\
Cement & 729.6 & 32.60 & 0.59 & 15.23 & 53.30 & 31.47 \\
$\begin{array}{c}\text { Fly ash I } \\
\text { (Sodeline) }\end{array}$ & 68.23 & 17.58 & 2.17 & 10.17 & 79.36 & 10.47 \\
$\begin{array}{c}\text { Fly ash II } \\
\text { (Soproline) }\end{array}$ & 48.17 & 17.68 & 3.79 & 7.34 & 88.87 & 3.79 \\
\hline
\end{tabular}

\section{Table1. Characteristic diameters and fraction of dredged sediment, cement and fly ashes}

In this study, to characterize the particle size distribution (PSD) of the dredged sediment and the fly ashes, a laser diffractometer Coulter LS2000 was used. As shown in Fig. 1, Sodeline and Soproline have different particle size distribution From the point of view of diameter particle most representative, Sodeline (34.58 $\mu \mathrm{m})$ has particles almost 2 times bigger than Soproline $(18 \mu \mathrm{m})$, regardless of the small different of percentage (see Table 1). Two fly ashes and a dredged sediment 
studied in these experiments contain an important quantity of silt fraction size sediments. Fig. 2 shows the linear relation between compressive strength and mean particle size of fly ash with $20 \%$ of cement replacement by fly ash with various mean particle sizes. This experiment result on ground coarse fly ash by $\mathrm{C}$. Jaturapitakkul et al [7] clearly showed that the compressive strength tends to reduce as the mean particle size increase for all curing ages. This maybe caused by coarse particles of FA reduces the ability of packing effect of fly ash and negatively affected on its pozzolanic activity. From a study of the strength contribution potential of seven bituminous fly ashes from the U.S., Mehta [11] reported that the particles larger than $45 \mu \mathrm{m}$ show little or no reactivity under normal hydration conditions and the pozzolanic activity was directly proportional to the amount of particles under $10 \mu \mathrm{m}$. From this theory we can observe that Sodeline has coarse particles $(>45 \mu \mathrm{m}) 1.6$ times $(21.04 \%)$ than Soproline $(12.78 \%)$ but in the same time Sodeline $(35.49 \%)$ has 1.35 times fine particles $(<10 \mu \mathrm{m})$ than Soproline (26.25). From this particle size point of view, we can expect that Soproline will be more reactive than Sodeline.

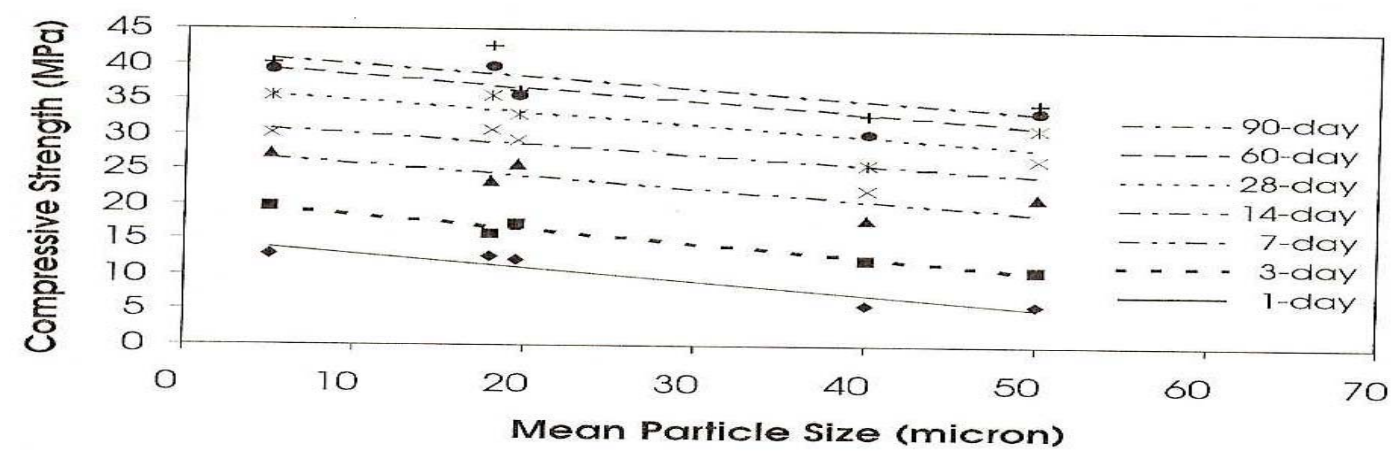

Fig.2.Relationship between compressive strength and mean particle size of fly ash [6]

\section{2. Chemical properties.}

As shown in Table 2 shows the differences in chemical analysis between Sodeline and Soproline which can influence the mechanical properties of the sediment stabilized. It can be seen that Soproline is characterised by a very high content of calcium oxide $(35.31 \%)$. On the other hand Sodeline has higher total amount of $\mathrm{SiO}_{2}, \mathrm{Fe}_{2} \mathrm{O}_{3}$ and $\mathrm{Al}_{2} \mathrm{O}_{3}(76.08 \%)$ content. According to ASTM C618-93 we can range Sodeline as class F fly ash, and Soproline as class C fly ash. According to Kolias et al [12] for lime-fly ash treated soil, the influence of soluble silica in strength is more pronounced than the effect of fineness at later ages. ASTM C618-98 [13] stated that to achieve high quality of pozzolans, the total amount of $\mathrm{SiO}_{2}, \mathrm{Fe}_{2} \mathrm{O}_{3}$, and $\mathrm{Al}_{2} \mathrm{O}_{3}$ should be similar or greater than $70 \%$, Sodeline $(76.08 \%)$ fully comply with this standard specification, and for Soproline the amount is only equal to $33.99 \%$. 


\begin{tabular}{ccccccccccc}
\hline $\begin{array}{c}\text { Oxide } \\
(\%)\end{array}$ & $\mathrm{SiO}_{2}$ & $\mathrm{Fe}_{2} \mathrm{O}_{3}$ & $\mathrm{Al}_{2} \mathrm{O}_{3}$ & $\mathrm{MgO}$ & $\mathrm{MnO}_{2}$ & $\mathrm{Na}_{2} 0$ & $\mathrm{~K}_{2} 0$ & $\mathrm{SO}_{3}$ & total $\mathrm{CaO}$ & free $\mathrm{CaO}$ \\
\hline Sodeline & 47.36 & 7.09 & 21.63 & 3.32 & 0.62 & 0.46 & 4.35 & 4.02 & 8.52 & 0.90 \\
\hline Soproline & 20.38 & 1.91 & 11.70 & 1.07 & 0.03 & 0.13 & 17.11 & 17.11 & 35.31 & 13.35 \\
\hline
\end{tabular}

Table2. Chemical analysis of Soproline and Sodeline

\section{Methods and results}

\section{1. 1. Preparation of specimens}

The dredged sediment, oven-dried for 5 days at $60^{\circ} \mathrm{C}$ was pulverized to $2 \mathrm{~mm}$ sieve size, it was initially mixed with determined quantities of fly ash, lime and cement as a binder, in a dry state and subsequently mixed with water by a mechanical mixer with a speed of $150 \mathrm{rd} / \mathrm{min}$ for a period of approximately 8 minutes. After mixing the specimens were prepared with the static compaction method, at the optimum moisture content and maximum density determined by Proctor test. Cylindrical specimens $(\varnothing=40 \mathrm{~mm}, \mathrm{~h}=80 \mathrm{~mm})$ were used for unconfined compressive strength testing. The compressive strength is determined using a $10 \mathrm{kN}$ capacity automatic compression machine according to EN 196-1 [14] on a simple speed cross-head moving machine at a speed of $1 \mathrm{~mm} / \mathrm{s}$. The specimens were pushed out from the mold directly after completion of the compaction and were stored in the curing room until testing at 7, 14, 28, 60 and 100 days. The specimens have been examined for their resistance in different extreme temperatures and for the effect of water immersions, they were also cured as the other specimens for 7 and 28 days and then they were subjected to 20 cycles consisting of 17 hours at $-10^{\circ} \mathrm{C}$ followed by 7 hours at $10^{\circ} \mathrm{C}$ (freeze-thaw test) and it is the same for the specimens examined for the effect of water immersion (wet-dry test) were subjected to 10 cycles consisting of 24 hours cured at $60^{\circ} \mathrm{C}$ followed by 24 hours immersed into water containers stored in the curing room.

\section{1. 2. Mix design}

The amount of cement was set to 5\%, amount that normally used in the road construction field. To study the influence of the fly ash, samples with different fly ash content were made. The goal of manufacturing CEM 2 and SD1 were to compare the reaction and strength gained to the combining fly ash, lime and cement treated samples (FA-L-C) with the same amount of binder. CEM 3 was performed to identify the behaviour of the stabilization process with maximum content of cement. The different formulas in this experiment are given in Table 3. 


\begin{tabular}{|c|c|c|c|c|c|}
\hline & & $\begin{array}{c}\text { FA I } \\
\text { (Sodeline)(\%) }\end{array}$ & $\begin{array}{c}\text { FA II (Soproline) } \\
(\%)\end{array}$ & $\begin{array}{c}\text { Lime } \\
(\%)\end{array}$ & $\begin{array}{c}\text { Cement } \\
(\%)\end{array}$ \\
\hline \multirow{5}{*}{ FA-L-C } & SD 1 & 5 & - & 2 & 1 \\
\cline { 2 - 6 } & SD 2 & 10 & - & 2 & 1 \\
\cline { 2 - 6 } & SD 3 & 15 & - & 2 & 1 \\
\cline { 2 - 6 } & SD 4 & 20 & - & 2 & 1 \\
\cline { 2 - 6 } & SD 5 & 30 & - & 2 & 1 \\
\cline { 2 - 6 } & SP3 & - & 30 & 2 & 5 \\
\hline \multirow{4}{*}{ Cement } & CEM 1 & - & & - & 8 \\
\cline { 2 - 6 } & CEM 2 & - & - & - & 11 \\
\cline { 2 - 6 } & CEM 1 & - & - & - & \\
\hline
\end{tabular}

Table3. Different compositions of binders

\section{2. Compaction test.}

To determine the influence of binder addition on decreasing the density of solid particles, $\rho \mathrm{s}$, solid particle density tests on dredged sediment in the natural state and with various binder additions were conducted. The test experiments were firstly conducted on the dredged sediment free from any binder addition as control for the others specimens. The next step was carried out with the binder-matrix ingredients. The used compaction procedures for the present study is the standard Proctor methods. From Fig. 3, we can observe that for any particular amount of binder addition in the dredged sediment, the dry unit weight decrease. It can be noticed too that the dry unit weight decrease with the increase in fly ash content. Maximum dry unit weight $\gamma_{\mathrm{dmax}}$ is recorded for dredged sediment free from binder $\left(1.16 \mathrm{~g} / \mathrm{cm}^{3}\right)$ and maximum dry density is lowest in the case of $30 \%$ fly ash content. The void ratio of soil depends upon the shape of the grains, the uniformity of grain size, and the uniformity of grain size and the conditions of the sedimentation.

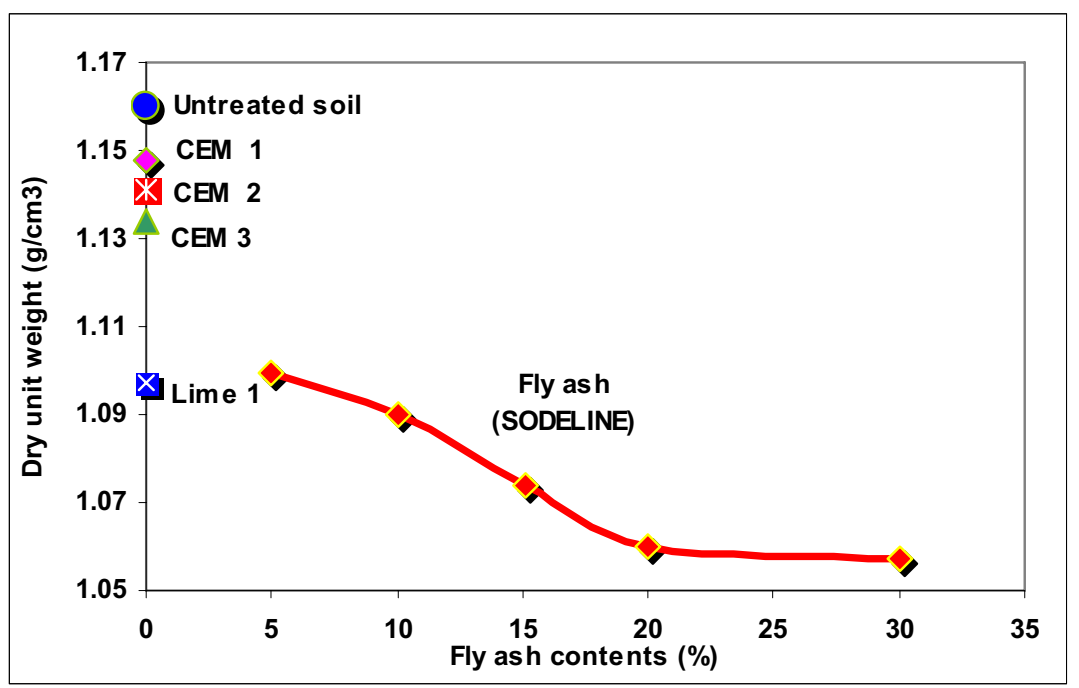

Fig. 3. Evolution of fly ash content with dry unit weight values 
The addition of binder changes the porosity and void ratio within the range of void ratio of fly ash, cement and soils. At maximum, the void ratio and porosity are free from moisture content. At the bulk density under compaction, the void ratio of the sediment and the porosity are minimum. On the other hand, the optimum moisture content $\mathrm{w}_{\text {opt }}$ increase with the increase of the binder.

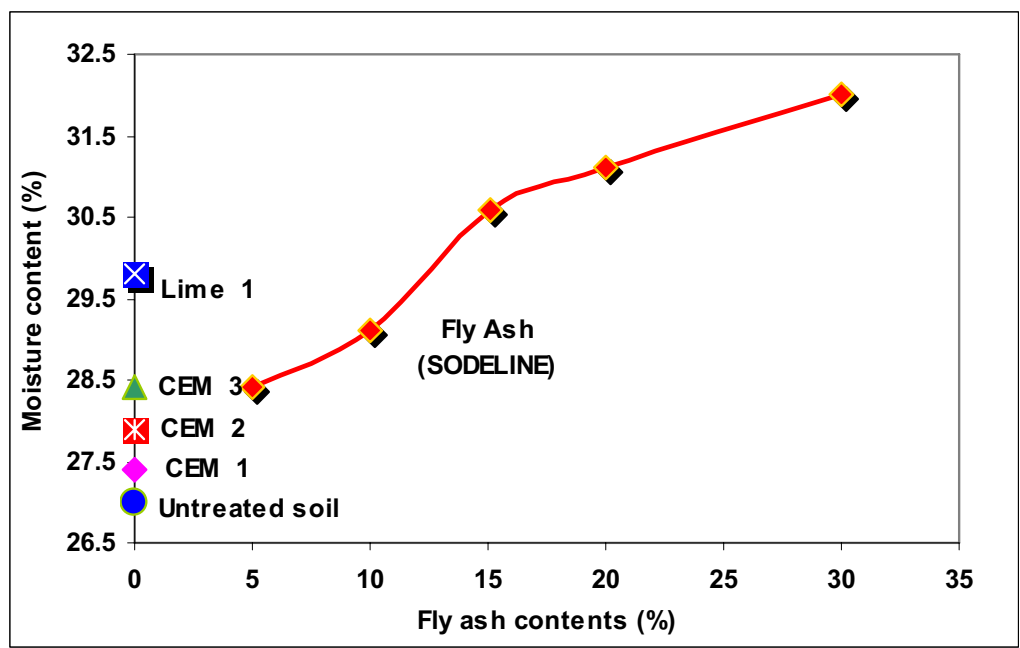

Fig. 4. Evolution of fly ash content with moisture content values

As shown in Fig 4, the optimum moisture content $\mathrm{w}_{\mathrm{opt}}$ for untreated dredged sediment is the minimum (27\%) among the others specimens and the optimum moisture content $\mathrm{w}_{\mathrm{opt}}$ increase along with the increase of binder content. Due to the lower specific gravity of the binder (fly-ash and cement) than that of the dredged sediment, the maximum dry density decreased and with the increasing of fly-ash contents meanwhile the optimum moisture content increased with increasing fly ash content

\section{3. Unconfined compressive strength (U.C.S)}

The U.C.S of soil is considerably one of the most important designing parameters used for pavement design highway construction that is why in this study we focused on the U.C.S properties. In Fig. 5, the gain in the U.C.S with respect to the curing period for dredged sediments with $5,10,15,20$, and 30 of fly ash contents. 


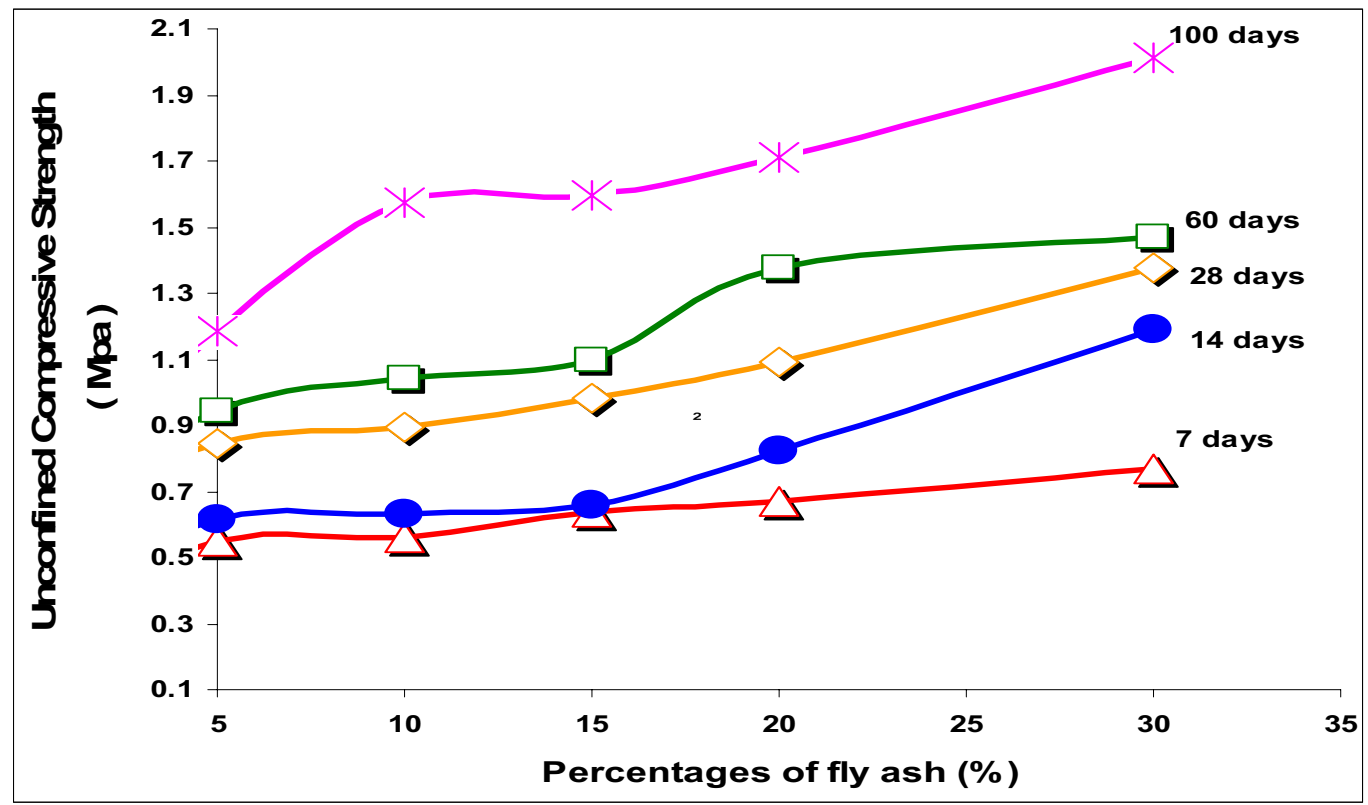

Fig.5. U.C.S development of solidified samples with fly ash content at different curing ages

It was observed that as the percentage of fly ash was used for the stabilization process increased, the value of the UCS also improves. The strength variation values for each sample show a big difference after 30 days of curing age, not like at 7 days of curing period, the different percentages of the fly ash didn't give a big difference on strength gain. We assumed at this curing period of 7 days the pozzolanic reaction was not completely achieved to provide the additional strength gain. We can assume that the strength gain is provided by the hydration of small amount of cement $(1 \%)$ and lime $(2 \%)$ in each samples. As already known that the hydration of the cement gives a rapid strength gain, while the lime generates heat which accelerates the cementitious and pozzolanic reaction. The hydration of the lime also produces large amounts of $\mathrm{Ca}(\mathrm{OH})_{2}$, required for the slower pozzolanic reaction in fly ash and for ion exchange in clays. For 14 days of curing periods specimens with $20 \%$ and $30 \%$ percentages of fly ash stated showing the important different strength values from others, it may be due to its high amount of fly ash that started to provide the additional strength gain by their roles as a micro-filler. As we can observe in Fig. 6 that beyond 60 days of curing period, the early strength value of the specimen stabilized with FA-L-C (SD1) was less than all specimens mixed with cement (CEM 1, 2 and 3). At 7 days to 14 days of curing period we can clearly see that the different U.C.S values was almost 2 times between samples treated with FA.L.C. and samples treated with cement, but after 100 days of curing period, specimen stabilized with FA-L-C obtained more strength values than specimens mixed with cement (CEM 2 and 3) and almost has the same strength values with CEM 3 (specimen with the highest cement content). 


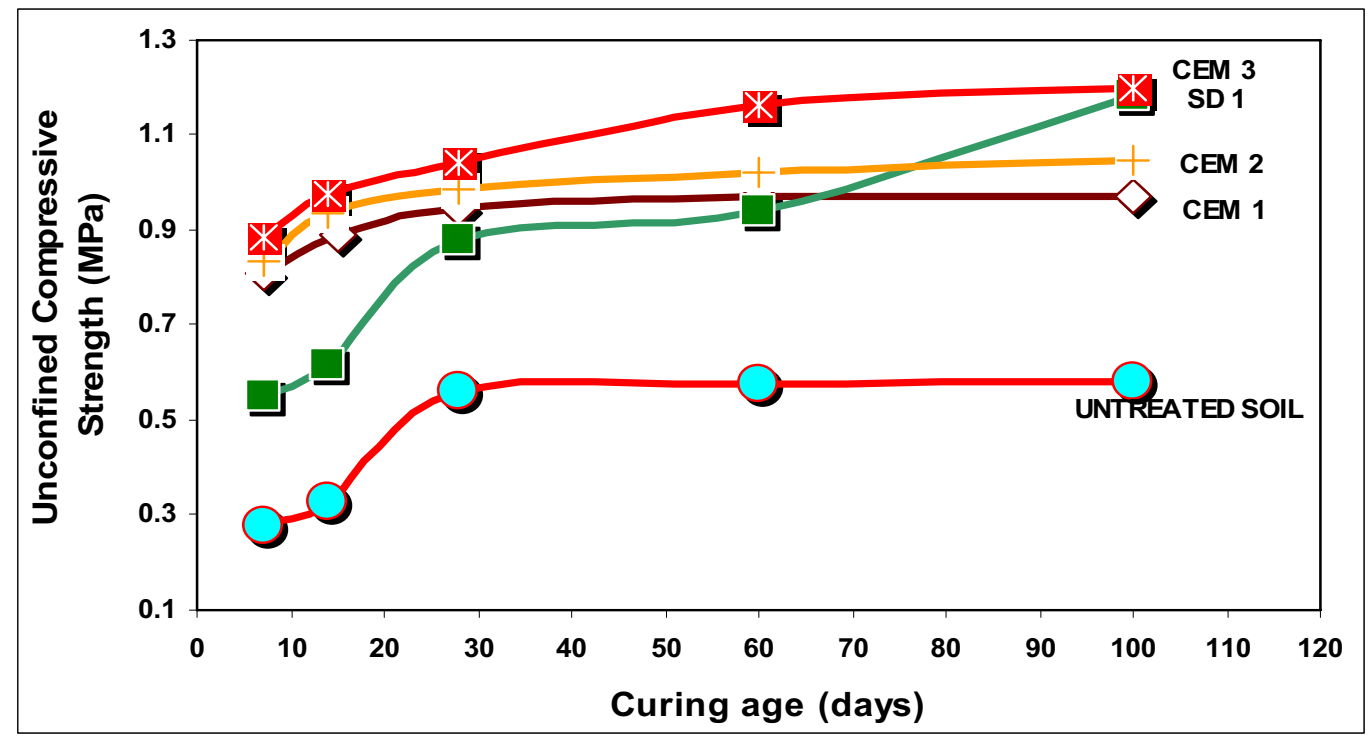

Fig. 6. U.C.S development of solidified samples at different curing ages

It may be due to the specimens stabilized with FA.L.C needs more time to react to achieve their maximum pozzolanic reaction. On one hand, the hydration of cement that provides its own pozzolans and therefore requires only a supply of water which directly started as the water introduces in to the mixture. But on the other hand the development of ultimate cured strength for FA.L.C treated sediment is gradual and continuous for several years.

\section{4. Cyclic weting-drying test.}

The previous experiments showed that the influence of cyclic wetting and drying (W-D) always related to the swelling behavior potential of the specimen treated [15], [16]. But this experiment in this study more interested on the influence of cyclic wetting and drying on its durability point of view. The specimens for this test were divided by two different days of curing, the first specimen series was cured for 7 days at $20^{\circ} \mathrm{C}$ and after the wet-dry cycles were applied for 20 cycles. For the second type of specimen series was cured for 28 days at $20^{\circ} \mathrm{C}$ before the W-D cycles were applied. This method was proposed by Stegemann and Cote [17]. The results of the test were reported in Fig. 7 and Fig. 8. For all the specimens cured at 7 days before subjected to W-D cycles (Fig. 7), there is any single specimen which could resists until the end of cycles of the W-D test (10 cycles), but from this result we can observed that the durability of the samples to water immersion constantly increase as the fly ash content increase. On the other hand, untreated sediment, specimen treated with $5 \%$ of cement (CEM1,) and FAL-C treated specimen with $5 \%$ of FA (SD1) immediately were dispersed on its structure due to water immersion for the first cycles 


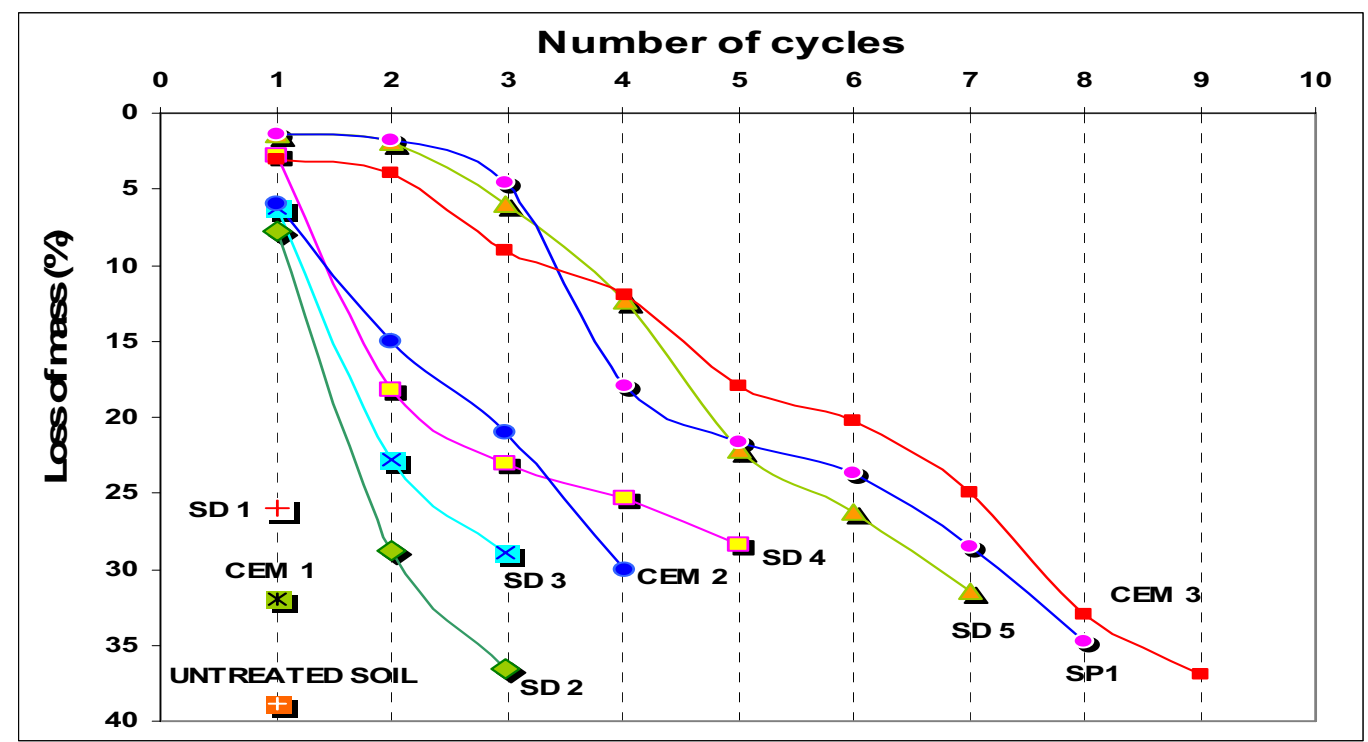

Fig. 7 Loss of mass of specimens with 7 days normal cured +20 days $W$-D cycles

As for the difference between Sodeline and Soproline, samples treated with the same amount of fly ash, even at this curing age the pozzolanic reaction was still not maximal yet but Soproline (SP1) shows more ability to resist the water immersion than Sodeline (SD 5). This may due the ability as space filler. As shown preciously Soproline has finer particle than Sodeline. Finer particles has better influence as a space filler, because fine particles of fly ash get absorbed on the oppositely-charged surface of sediment particles and prevent them from flocculation, and automatically reduce the void space and gives a lower porosity, so the samples will not trap a large amounts of water when the W-D test occurs. We believed that this theory can prove too why the durability of W-D test increase with the increase of the fly ash. And for compare the durability between cement treated sample and FA.L.C treated sample, the results for 7 days of curing normal shows that cement treated sample (CEM2) has more durability ( 3 cycles of W-D test) than sample treated with FA.L.C (SD1), this results similar with previous test (U.C.S) As noted before that cement reacts rapidly, that is why at short curing period CEM 2 has more performance on W-D test than SD1. At 28 days curing period, even the reaction pozzolanic in these specimens was still not reacting maximally, but the almost all specimens showed an improvement of durability to W-D test except untreated soil. As shown in Fig. 8, the specimen with 25\% and $30 \%$ fly ash content (SD4, SD5 and SP1) were successfully passed all the 10 cycles of W-D test. As the pozzolanic reaction continues with the curing ages, produce stronger bonding between the particles, so it becomes more difficult for the water to penetrate into the matrix. And as the result of this reaction we can see that CEM3 was outperformed by the SP1 and SD5 on the loss of mass point of view. As for comparison of FA.L.C treated sample and cement treated sample, CEM 2 still has the better durability to water immersion from SD1. And we can 
note that at 28 days curing period, Soproline (SP1) still performed better than Sodeline (SD5).

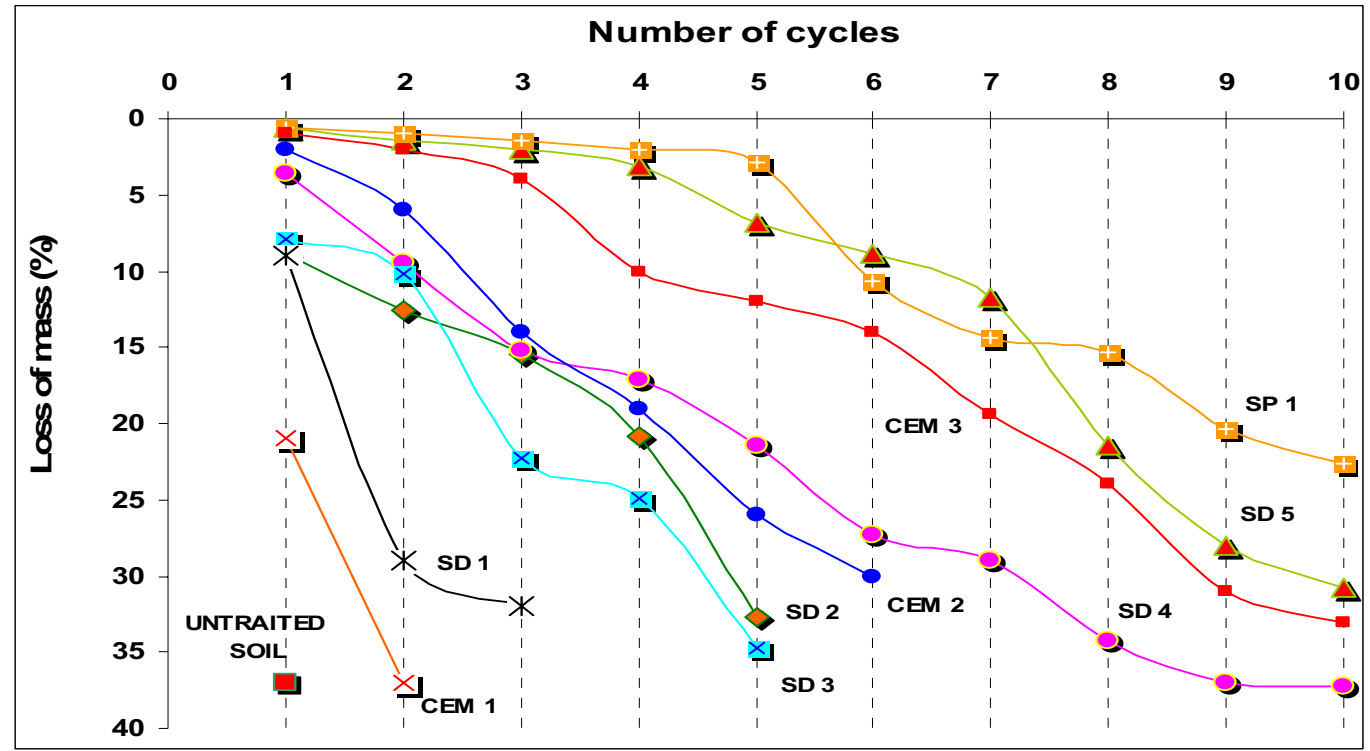

Fig.8 Loss of mass of specimens with 28 days normal cured +20 days $W$-D cycles

\section{Conclusions}

The main objectives of these experiments were to identify the influence of the binder especially fly ash, on the strength behavior and its strength durability on the extreme conditions. The improvement in mechanical properties such as optimum moisture content, and unconfined compressive strength values were investigated. Untreated sediment mixture, sediment-cement mixture, and sediment-fly ash-lime-cement (FA.L.C) mixture were prepared and compacted at the optimum water content. Unconfined compressive strength tests were then performed on these mixtures in normal conditions and in extreme conditions. The UCS value gained by specimen treated with FA.L.C was continuously increase up to 100 days, and even higher than specimens treated by cement after 100 days of curing period, and we can note as well that the increase of the percentages of fly ash clearly showed the increase on U.C.S strength values. For the specimens treated by cement, the increase variation of UCS value strength after 60 days is not as intense as before. The results of wetting and drying test showed that the specimens treated with FA.L.C due to its slow pozzolanic reaction, need more time to bond the particles against the immersion on water, only with its role as micro filler, the specimens could not resists until the end of the W-D test. On the other hand after 28 days of curing on normal condition the specimens treated with FA.L.C showed an important increase on their durability on W-D test, but only specimens with 25 and $30 \%$ percentages of fly ash content can pass until the end of he W-D test. From this W-D test we can conclude too that Soproline showed a better performance than Sodeline due to its mineralogical characteristics and its finer particles size. The research has shown that, from the comparison of these 
three various specimens, the addition of fly ash may be considered as an interesting alternative for stabilization of dredged sediments

\section{References}

[1] Colin, D. (2003). Valorisation de sediments fin de dragage en technique routière. Thèse de l'université de Caen, France, pp 181

[2] Dubois, V (2006). Caractérisation physico-mécanique et environnementale des sédiments marins. Application en technique routière. Thèse, Ecole des Mines de Douai, France, pp 311.

[3] Zentar, R., Dubois, V., Abriak. N. E., (2008) Mechanical behaviour and envorinmental impacts of a test road built with marine dredged sediments. Resource, Conservation and Recycling 52, 2008, pp 947-954.

[4] Kamali, S., Bernard, F., Abriak., N., E., Degrugilliers, P., (2008) Marine dredged sediments materials resource for road construction. Waste Management 28, pp 919-218.

[5] Seung L.W., Fishman K. L.(1993) Resilient and plastic behaviour of classifier tailing and fly ash mixtures. Transport Research Record, volume 1418/1993, pp51-59.

[6] P. K. Mehta (1985) Influence of fly ash characteristics on the strength of Portland-Fly ash mixture. Cem Con Res 15, pp 669-674.

[7] C. Jaturapitakkul, K. Kiattikomol and S. Songpiriyakij (1999) A study of strength activity index of ground coarse fly ash with Portland cement. Science Asia 25, pp 223-229.

[8] Giergiczny, Z., Werynska., A (1989) Influence of fineness of fly ash on their hydraulic activity. Fly ash, Silica Fume, Slag and Natural Pozzolans in Concrete, Proceedings $3^{\text {rd }}$ International Conference, Trondheim, Norway, SP 114, pp 97-115.

[9] Binici H., Aksogan O.,. Cagatay I. H., Tokyay M., Emsen E., (2007). The effect of particle size distribution on the properties of blended cements incorporating GGBFS and natural pozzolan, Powder Technology, volume 177/2007, pp 140-147.

[10] Joshi, R. C and Lohtia, R.P (1997): "Fly Ash in concrete, Production, properties, and uses". Gordon and Breach Science Publisher volume 2/1997, pp27-29.

[11] Mehta P. K. (1985) Influence of fly ash characteristics on the strength of Portland cement-fly ash mixtures, Cement nd Concrete Research, vol.15, PP. 669-674.

[12] Kolias S., Kasselouri-Rigopoulou V., Karahalios A. (2005) Stabilization of clayey soil with high calcium fly as hand cement. Cement and Concrete Composites 27 (2005) pp 301-313.

[13] ASTM C-618-98, Standard specification for Coal Fly Ash and Raw or Calcined Natural Pozzolans for Use as a Mineral Admixture in Concrete, American Society for testing and materials 
[14] NF EN 196-1, (1995) Méthodes d'essais des ciments. Partie 1: détermination des résistances mécaniques.

[15] Day R. W. (1994). Swell-shrink behaviour of compacted clay. Journal of Geotechnical Engineering, volume 120/ 1994, No.3, pp 618-623.

[16] Rao S. M., Reddy B. V. V., Muttharam M. (2001). The impact of cyclic wetting drying in the swelling behaviour of stabilized expansive soils. Engineering Geology 2001, volume 60/ 2001, pp 223-233.

[17] Stegemann J. A., Cote P. L., (1992) Protocole d'évaluation proposé pour les déchets solidifiés à base de ciment, Série de la protection de l'environnement SPE3/HA/9, Environnement Canada, 66 p.

[18] NFP 98-234-1 (1992) Essai relatifs aux chaussées, comportement au gel des matériaux traités aux liants hydrauliques. Partie 1: Essai de résistance au gel-dégel des graves et sables traités. 